\title{
Preserving Digital Materials
}

Kapena Shim, Master's Candidate, Library \& Information Science, UH Mānoa

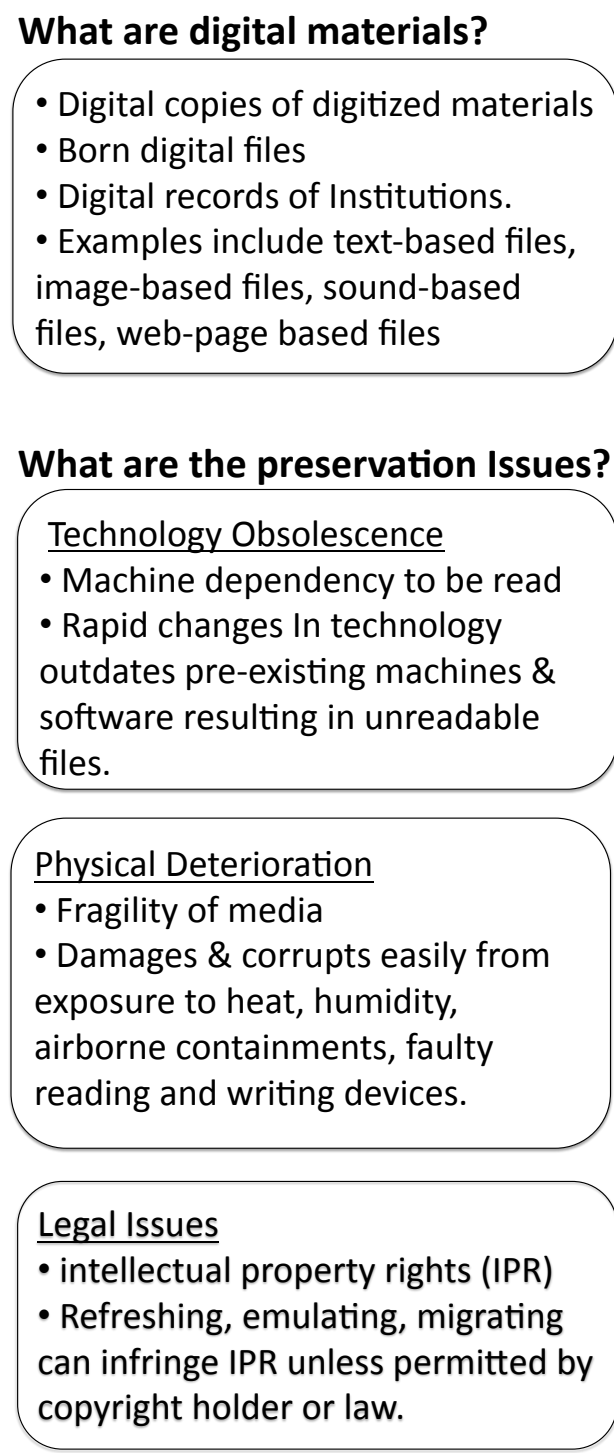

\section{Preservation Precautions}

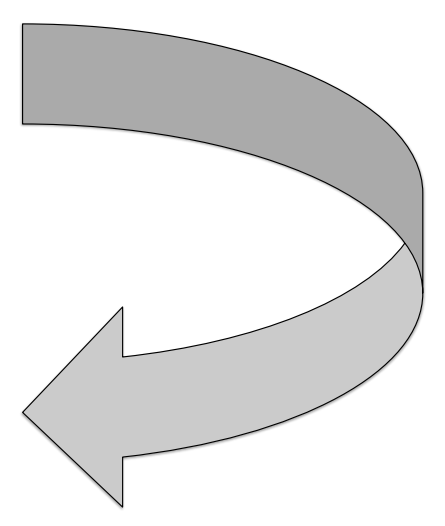

- Stable, safe storage

- Controlled environment

- Regular refreshment cycles onto new media

- Make preservation copies

- Handle properly

- Transfer to standard storage media

- Use standard files and media formats

- Detailed metadata documentation

Technology Obsolescence

- Machine dependency to be read

- Rapid changes In technology

outdates pre-existing machines \&

software resulting in unreadable

- Fragility of media

- Damages \& corrupts easily from

exposure to heat, humidity,

orne containments, faulty
Legal Issues
- intellectual property rights (IPR)
- Refreshing, emulating, migrating copyright holder or law. 